\title{
Clinical presentation and management of diabetes mellitus in pregnancy
}

This article was published in the following Dove Press journal:

International Journal of Women's Health

9 December 2013

Number of times this article has been viewed

\section{Nasser Al-Azemi' \\ Michael F Diejomaoh ${ }^{1,2}$ \\ Elisavet Angelaki' \\ Asiya T Mohammed ${ }^{2}$}

'Maternity Hospital, Shuwaikh, Kuwait; ${ }^{2}$ Department of Obstetrics and Gynecology, Faculty of Medicine, Kuwait University, Safat, Kuwait
Correspondence: Michael F Diejomaoh Department of Obstetrics and Gynecology, Faculty of Medicine, Kuwait University, PO Box 24923. Safat I3I I0, Kuwait

Tel +965253 | 960 ।

Fax +965 25338906

Email michaeldiejo@hotmail.com
Objective: To evaluate the clinical presentation, management, and the outcome of diabetes mellitus in pregnancy.

Methods: One hundred seventy-one patients with diabetes mellitus admitted between September 1, 2006, and June 30, 2008, to the labor room at Maternity Hospital in Kuwait for induction of labor made up the study population; while an equivalent number of patients without medical complications who also were admitted for induction of labor made up the control group. The patients were assessed at admission, and their medical data were extracted. The study and control patients were monitored through labor/puerperium, and the outcome was documented. Results: Gestational diabetes mellitus was diagnosed in $71.9 \%$ of the study patients, a past history of diabetes mellitus was recorded in $81.34 \%$ of the study patients, and $49.2 \%$ of the patients were admitted at 8-12 weeks of gestation for diabetic control. The mean weight gained in pregnancy was significantly higher for control patients $(11.52 \pm 5.643$ versus [vs] $\left.9.90 \pm 5.757 \mathrm{~kg} / \mathrm{m}^{2} ; P<0.009\right)$, and the body mass index of study patients was higher $\left(32.00 \pm 6.160\right.$ vs $\left.28.20 \pm 5.885 \mathrm{~kg} / \mathrm{m}^{2} ; P<0.0001\right)$. Of the study population, $64.3 \%$ of the patients were managed with diet and increased physical activity and $35.7 \%$ with insulin, diet, and increased physical activity. The incidences of maternal morbidity in both study and control groups were comparable, and the incidence of preeclampsia was low, at $2.3 \%$. The gestational age at delivery was higher in the control group ( $39.02 \pm 1.834$ weeks vs $38.62 \pm 1.773$ weeks; $P<0.0001$ ), and the percentage of cesarean deliveries was higher in the study population $(44.4 \%$ vs $33.3 \% ; P=0.046)$. The Apgar scores of the both groups were comparable and in the normal range, and the incidences of fetal anomaly (1.17\%), shoulder dystocia (1.8\%), and Erb's palsy (1.8\%) were low.

Conclusion: Gestational diabetes mellitus was diagnosed in $71.9 \%$ of the diabetic patients studied, and dietary control and increased physical activity were the main modalities of management. There was an increased rate of cesarean section in the study population, the incidences of maternal and perinatal morbidity were low, and the perinatal outcomes were satisfactory.

Keywords: clinical features, diagnosis, GDM treatment outcome

\section{Introduction}

Diabetes mellitus is one of the most frequently encountered medical disorders complicating the course of pregnancy. ${ }^{1,2}$ The incidence of diabetes mellitus is increasing worldwide, and this trend is particularly remarkable in developed countries, where a rising incidence of obesity has been identified as a contributory factor. Diabetes mellitus in pregnancy may be pre-gestational in onset, either as type 1 (insulin-dependent) or type 2 (non-insulin dependent) diabetes mellitus, as reported in $1 \%$ of pregnancies. ${ }^{1-3}$ It may also be gestational diabetes mellitus (GDM), defined as any degree of glucose or carbohydrate intolerance first diagnosed or recognized during pregnancy, ${ }^{4-8}$ which 
has been reported to occur in $2 \%-9 \%$ of all pregnancies. ${ }^{4,9,10}$ Whereas GDM has been reported to account for $90 \%$ of all cases of diabetes mellitus in pregnancy, ${ }^{1,8,11}$ Type 2 diabetes mellitus accounts for $8 \%{ }^{8}$

Fifty percent of pregnancies in the United States are unplanned; the rate of unplanned pregnancies in Western Europe is about $20 \%{ }^{12}$ The incidence of unplanned pregnancies in Kuwait is not well established but is estimated to be quite high. Maternal and neonatal complications have been associated with diabetes mellitus in pregnancy, and the positive role of preconception counseling in reducing such complications has been confirmed. ${ }^{13}$ Such counseling is aimed at achieving adequate glycemic control before the onset of the pregnancy to ensure a reduction in the incidence of complications. The incidence of fetal anomaly has been reported to be as high as $18 \%{ }^{14}$ in women with preexisting diabetes mellitus, but with aggressive preconception and first trimester management of the diabetes, such rates have been reported to be as low as $5.1 \%$ to $9.8 \% .^{15,16}$ In spite of the reported benefits of pre-pregnancy counseling in diabetes mellitus, the degree of use of such services by patients has not been widely established.

The clinical presentation of diabetes mellitus in pregnancy may be quite varied, but the classical triad of the symptoms of polydipsia, polyphagia, and polyuria may not be reported by most patients during pregnancy. The patients may present with previous history of medical complications of diabetes mellitus (chronic hypertension/chronic renal disease) and obesity. The gestational age at presentation of these diabetic patients could influence pregnancy outcome.

The management of pre-gestational diabetes mellitus should commence preconception and extend through antenatal, intrapartum, and postnatal periods and aim at maternal normal glycemia. ${ }^{17}$ This, in turn, should contribute to lower rates of congenital fetal malformations and maternal complications, such as preeclampsia, ${ }^{17}$ but in spite of such efforts, it should be noted that there is still a risk for fetal death in diabetes mellitus. ${ }^{18}$ The management of GDM still attracts some controversy regarding the exact modality of treatment to be used: lifestyle changes, diet and adjusted doses of insulin, or the emerging trend of the use of oral hypoglycemic drugs. ${ }^{19-22}$ There is, however, some agreement on the benefits of treating GDM, as untreated gestational diabetes has been associated with significant risks of perinatal morbidity in all levels of disease severity, ${ }^{23}$ and treatment has been associated with reduced perinatal complications and maternal morbidity. ${ }^{6,10,19,22}$

The incidence of diabetes mellitus is high in Kuwait ${ }^{24}$ and will continue to increase ${ }^{25}$ in view of the increasing incidence of obesity in the population. Therefore, the aim of our study was to evaluate the clinical presentation and management of diabetes mellitus in pregnancy and establish their effect on the outcome of pregnancy.

\section{Methods}

One hundred seventy-one patients with diabetes mellitus who had singleton pregnancies were identified as the study population. These patients, admitted for induction of labor between September 1, 2006, and June 30, 2008, were recruited as soon as they were admitted into the labor ward of the Maternity Hospital in Kuwait. Another 171 patients with singleton pregnancies and no medical complications who were also admitted into the labor ward of the Maternity Hospital for induction of labor during the same period, immediately after the index study patients, served as the control population. The patients who were admitted with diabetes mellitus in pregnancy were those previously diagnosed antenatally as having pre-gestational diabetes mellitus (type 1 or type 2 diabetes mellitus) or GDM. The diagnosis of GDM was based on the detection of the following: at least two abnormal blood glucose results higher than the normal ranges for our laboratory (subsequent to a $75 \mathrm{~g}$ oral glucose tolerance test [OGTT] preceded by a 12 hour overnight fast); this modality of OGTT is based on the World Health Organization recommendations. ${ }^{26}$ The normal blood glucose ranges for our laboratory at the time of the study after OGTT were fasting blood glucose levels of $5.3 \mathrm{mmol} / \mathrm{L}$ or lower; first hour levels of $10 \mathrm{mmol} / \mathrm{L}$ or lower; and second hour levels of $8.6 \mathrm{mmol} / \mathrm{L}$ or lower.

The study and control patients were interviewed at admission to the labor ward by two of the authors. Informed consent was obtained from the patients. Official approval was obtained from the Hospital Scientific Committee before the commencement of the study, which was carried out following the principles in the Declaration of Helsinki.

The biodata of the study patients and control patients were documented. Details of antenatal events, including the total weight gained all through pregnancy, the weight profile of the patients, any antenatal complications, the management followed, and the course of the current index pregnancy, and all the events antedating the onset of admission were also extracted from the medical files and recorded. The patients' past gynecological, obstetric, medical, and surgical history, as well as their family and social history, also were obtained from the files by the same two authors, who also performed complete physical examinations on all of the patients. The patients were monitored throughout the 
labor and puerperium. The intrapartum course of the patients and the gestational age at delivery, any antenatal/intrapartum complications (pregnancy induced hypertension/ pre-eclampsia/premature rupture of membranes/pyrexia, etc), mode of delivery, fetal complications in labor, Apgar score, fetal birth weight, and the perinatal outcome were documented. The postpartum course of the patients was followed-up and documented.

\section{Statistical analysis}

The information and the data collected from and on the study and control patients were analyzed using SPSS version 19 (IBM Corporation, Armonk, NY, USA). The statistical analyses were performed using the $\chi^{2}$ test, Fisher's exact test, and Student's $t$-test; $P$-values $\leq 0.05$ were regarded as significant.

\section{Results}

The clinical characteristics of the study and control population are given in Table 1. Although there was no statistical difference in the proportion of Kuwaitis (60.5\% versus [vs] $56.7 \%$ ) and non-Kuwaitis (39.5\% vs $43.3 \%$ ) in the study and

Table I Clinical characteristics of the patients studied: study and control population

\begin{tabular}{|c|c|c|c|}
\hline Event & $\begin{array}{l}\text { Study } \\
\text { population } \\
(n=|7|)\end{array}$ & $\begin{array}{l}\text { Control } \\
\text { population } \\
(n=|7|)\end{array}$ & $P$-value \\
\hline \multicolumn{4}{|l|}{ Ethnicity } \\
\hline Kuwaiti & $31(18.1)$ & $30(17.5)$ & NS \\
\hline \multicolumn{4}{|l|}{ Non-Kuwaitis } \\
\hline Arabs & $65(38.0)$ & $7 \mid(4 I .5)$ & NS \\
\hline Indians & $40(23.4)$ & $30(17.5)$ & NS \\
\hline Filipinos & II (6.4) & $7(4.1)$ & NS \\
\hline Pakistanis & $7(4 . I)$ & $7(4.1)$ & NS \\
\hline Others & $17(9.9)$ & $26(15.2)$ & NS \\
\hline Age, years (range) & $\begin{array}{l}31.92 \pm 5.625 \\
(21-43)\end{array}$ & $\begin{array}{l}28.31 \pm 5.651 \\
(19-31)\end{array}$ & $<0.0001$ \\
\hline Parity (range) & $\begin{array}{l}2.14 \pm 1.971 \\
(0-8)\end{array}$ & $\begin{array}{l}1.26 \pm 1.469 \\
(0-5)\end{array}$ & $<0.0001$ \\
\hline Miscarriages & $0.54 \pm 0.315$ & $0.46 \pm 0.342$ & $<0.0001$ \\
\hline Mean weight, kg & $81.58 \pm 16.212$ & $72.47 \pm 15.485$ & $<0.0001$ \\
\hline $\begin{array}{l}\text { Total weight } \\
\text { gained, kg }\end{array}$ & $9.90 \pm 5.757$ & $11.52 \pm 5.643$ & $<0.009$ \\
\hline $\begin{array}{l}\text { Body mass index, } \\
\mathrm{kg} / \mathrm{m}^{2} \text { (range) }\end{array}$ & $\begin{array}{l}32.00 \pm 6.160 \\
(21-57)\end{array}$ & $\begin{array}{l}28.20 \pm 5.885 \\
(20-38)\end{array}$ & $<0.0001$ \\
\hline *Kuwaiti & 60.5 & 56.7 & NS \\
\hline *Non-Kuwaiti & 39.5 & 43.3 & NS \\
\hline
\end{tabular}

Notes: For age, parity, miscarriages, mean weight, total weight gained, and body mass index, data are expressed as mean \pm standard deviation. All other data are expressed as number and percentage. Mean weight is the mean weight at the first booking visit. *These data were arrived at using a modified analysis and re-arrangement of the Ethnic groups.

Abbreviation: NS, not significant. control patients, respectively; there were more Indians and fewer non-Kuwaiti Arabs in the study population compared with the control group. The mean age, parity, and number of miscarriages were significantly higher in the study group $(P<0.0001)$. Although the mean weight at booking and the body mass index (BMI) were significantly higher in the study group $(81.58 \pm 16.212 \mathrm{vs} 72.47 \pm 15.485 \mathrm{~kg}$ and $32.00 \pm 6.160 \mathrm{vs}$ $28.20 \pm 5.885$, respectively; $P<0.0001$ ), the total weight gained was significantly higher in the control population

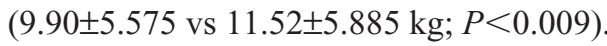

We have also performed further analysis of some of the clinical characteristics of the patients in the study group, which was divided into the three subgroups of diabetes mellitus as diagnosed in the current study. These subgroups, which will be highlighted in Table 4, were as follows: GDM, type1 diabetes mellitus, and impaired glucose tolerance (IGT). There was no significant difference in the mean age of the subgroups versus the control ( $32.15 \pm 5.507$ vs $31.24 \pm 6.663$ years $[P=0.498]$ and $32.15 \pm 5.507$ vs $31.41 \pm 5.458$ years $[P=0.527])$, although the mean ages of all three subgroups were significantly higher than the control group $(P<0.0001, \mathrm{P}<0.029$, and $\mathrm{P}<0.008$, respectively; Table 2). There was also no significant difference between the parity of the three subgroups, although the parity of the GDM and type 1 diabetes mellitus subgroups was significantly higher than that of the control group $(2.19 \pm 2.128$ vs $1.26 \pm 1.469[P<0.0001]$ and $2.43 \pm 1.363$ vs $1.26 \pm 1.469$ $[P<0.0006])$. The mean weight at booking and the mean BMI of the three diabetic subgroups were comparable, although the data for the GDM and IGT were significantly higher than for the control. Whereas the mean weight gained in all the diabetic subgroups was comparable, the numbers for the control group were significantly higher than for the GDM and IGT subgroups $(11.52 \pm 5.643$ vs $10.17 \pm 6.008 \mathrm{~kg}[P=0.049]$ and $11.52 \pm 5.643$ vs $8.33 \pm 4.848 \mathrm{~kg}[P=0.006])$. The mean glycosylated hemoglobin $A_{1 c}$ level in the GDM and type 1 diabetes subgroups were comparable but were highest in the IGT subgroup; this level was significantly higher than in the other two subgroups $(5.56 \pm 1.147$ vs $6.13 \pm 0.734[P=2.990]$ group A vs $\mathrm{B}, 5.56 \pm 1.147$ vs $6.65 \pm 0.6[P<0.0001]$ group $\mathrm{A}$ vs $\mathrm{C}$, and $6.13 \pm 0.734$ vs $6.65 \pm 0.6[P=0.009]$ group $\mathrm{B}$ vs $\mathrm{C}$, respectively).

A previous history of pre-gestational diabetes mellitus was recorded in $73.7 \%$ of the study group (previous type 2 diabetes mellitus: 107 patients [62.6\%]; type 1 diabetes mellitus, 19 patients [11.1\%]; Table 3). Only 39 (22.8\%) patients volunteered a history of previous GDM in previous pregnancies. It is pertinent to emphasize here that the data presented in Table 3 refer to the recording of the events in 
Table 2 Clinical characteristics of the diabetic subgroups and control population

\begin{tabular}{|c|c|c|c|c|c|}
\hline Event & $\begin{array}{l}\text { Group A, gestational } \\
\text { DM }(n=\mid 23)\end{array}$ & $\begin{array}{l}\text { Group B, type I } \\
\text { DM }(n=21)\end{array}$ & $\begin{array}{l}\text { Group C, } \\
\text { IGT }(n=27)\end{array}$ & $\begin{array}{l}\text { Group D, control } \\
(n=|7|)\end{array}$ & $P$-value \\
\hline Age, years (range) & $32.15 \pm 5.507(2 \mid-45)$ & $31.24 \pm 6.663(2 \mid-43)$ & $3 I .4 I \pm 5.458(2 I-42)$ & $28.3 I \pm 5.65 \mid(|9-3|)$ & $\begin{array}{l}\text { I. } 0.498 \\
\text { 2. } 0.527 \\
\text { 3. }<0.000 \text { I* } \\
\text { 4. } 0.923 \\
\text { 5. } 0.029 * \\
\text { 6. } 0.008^{*}\end{array}$ \\
\hline Parity (range) & $2.19 \pm 2.128(0-8)$ & $2.43 \pm 1.363(0-5)$ & $1.70 \pm 1.564(0-5)$ & $1.26 \pm 1.469$ & $\begin{array}{l}\text { I. } 0.50 \text { I } \\
\text { 2. } 0.263 \\
\text { 3. }<0.000 I^{*} \\
\text { 4. } 0.109 \\
\text { 5. }<0.0006 * \\
\text { 6. } 0.156\end{array}$ \\
\hline $\begin{array}{l}\text { Mean weight, } \\
\text { kg (range) }\end{array}$ & $82.29 \pm 15.596(2 \mid-49)$ & $77.38 \pm|4.54|(20-40)$ & $81.59 \pm 19.947(2 \mid-57)$ & $72.47 \pm 15.485$ & $\begin{array}{l}\text { I. } 0.18 \mathrm{I} \\
\text { 2. } 0.865 \\
\text { 3. }<0.000 I^{*} \\
\text { 4. } 0.420 \\
\text { 5. } 0.169 \\
\text { 6. } 0.030 *\end{array}$ \\
\hline $\begin{array}{l}\text { Body mass index, } \\
\mathrm{kg} / \mathrm{m}^{2}\end{array}$ & $32.45 \pm 5.828$ & $30.15 \pm 6.669$ & $31.7 \pm 6.899$ & $28.20 \pm 8.885$ & $\begin{array}{l}\text { I. } 0.104 \\
\text { 2. } 0.559 \\
\text { 3. }<0.000 \text { I* } \\
\text { 4. } 0.438 \\
\text { 5. } 0.159 \\
\text { 6. } 0.005^{*}\end{array}$ \\
\hline $\begin{array}{l}\text { Mean weight } \\
\text { gained, kg }\end{array}$ & $10.17 \pm 6.008$ & $10.00 \pm 5.568$ & $8.33 \pm 4.848$ & $11.52 \pm 5.643$ & $\begin{array}{l}\text { I. } 0.903 \\
\text { 2. } 0.139 \\
\text { 3. } 0.049 * \\
\text { 4. } 0.273 \\
\text { 5. } 0.244 \\
\text { 6. } 0.006 *\end{array}$ \\
\hline $\begin{array}{l}\text { Mean glycosylated } \\
\text { hemoglobin } \\
A_{\text {Ic }} \text { (range) }\end{array}$ & $5.56 \pm 1.147(5.2-6.72)$ & $6.13 \pm 0.734(5.1-7.11)$ & $6.65 \pm 0.6(6 . \mid-7.23 I)$ & - & $\begin{array}{l}\text { I. } 2.990 \\
\text { 2. }<0.000 I^{*} \\
\text { 3. } 0.009 * \mathrm{~A} \\
\text { versus C }\end{array}$ \\
\hline
\end{tabular}

Notes: I, A versus B; 2, A versus C; 3, A versus D; 4, B versus C; 5, B versus D; and 6, C versus D. All data are mean \pm standard deviation. *Indicates statistically significant. Abbreviations: DM, diabetes mellitus; IGT, impaired glucose tolerance.

the past medical history of the patients studied; the figures and percentages do not refer to incidences in the current index pregnancies under study. The patients in the study population also presented with a past history of events, such as previous high birth weight (10.5\%), recurrent moniliasis (5.3\%), and previous still birth $(2.3 \%)$, which tend to be more associated with diabetes mellitus.

During the study, the practice in our department was to subdivide/classify all cases of diabetes mellitus in pregnancy into 3 subgroups: GDM, type 1 diabetes mellitus, and IGT, which is synonymous with impaired glucose metabolism. This classification is reflected in Table 4. Type 2 diabetes mellitus was not identified as a separate entity. GDM was diagnosed in $71.9 \%$ of the study population, and type 1 diabetes mellitus was the diagnosis in $12.3 \%$ of the study group (Table 4). Of the patients in the study population, $88.8 \%$ were admitted at various periods of their pregnancy for further blood glucose monitoring and adjustments in diabetic control, and $49.2 \%$ of the patients were actually admitted between 8 and 12 weeks gestation to adjust and regulate their diabetic control. The blood glucose levels of the patients were closely monitored with multiple point tests. Preprandial blood glucose levels were maintained at $5.3 \mathrm{mmol} / \mathrm{L}$ or lower, and postprandial blood glucose levels at $7.3 \mathrm{mmol} / \mathrm{L}$ or lower, and the glycosylated hemoglobin $\mathrm{A}_{1 \mathrm{c}}$ levels were reported to be mostly between $5.5 \%$ and $6.2 \%$ (a range that denotes satisfactory control) the range of glycosylated hemoglobin $\mathrm{A}_{1 \mathrm{c}}$ levels reported in the three diabetic subgroups was between 5.2\% and 7.231\% [Table 2], and the levels were highest in the IGT group, although the 
Table 3 Significant events in the past obstetric history of the study population $(n=|7|)$

\begin{tabular}{lll}
\hline Event & Cases $(\mathbf{n})$ & Percentage \\
\hline Previous GDM & 39 & 22.8 \\
Previous NIDDM & 107 & 62.6 \\
Previous IDDM & 19 & 11.1 \\
Previous big babies & 18 & 10.5 \\
Previous SB & 4 & 2.3 \\
Previous NND & 3 & 1.8 \\
History of recurrent moniliasis & 9 & 5.3 \\
History of infertility & 13 & 7.6 \\
\hline
\end{tabular}

Note: Some patients who gave a past history of GDM also had a past history of previous NIDDM.

Abbreviations: GDM, gestational diabetes mellitus; IDDM, insulin-dependent diabetes mellitus (type I diabetes mellitus); NIDDM, non-insulin dependent diabetes mellitus (type 2 diabetes mellitus); NND, neonatal fetal death; SB, still birth.

levels in the GDM and type 1 diabetes mellitus subgroups were comparable.

Fifty-six percent of our diabetic patients (both GDM and type 1 diabetes mellitus patients) engaged in home blood glucose monitoring. The patients were seen regularly in the dedicated diabetic clinics, which were linked to the antenatal clinics, where their blood glucose levels were checked. Whereas a majority of the study patients (64.3\%) were managed with dietary control and lifestyle changes, $35.7 \%$ were managed with multiple varied daily doses of insulin injections, dietary control, and lifestyle changes. It is pertinent to state here that all 21 patients diagnosed as having type 1 diabetes mellitus were managed on insulin injections, diet, and lifestyle changes, whereas the 27 patients with IGT were managed on diet and lifestyle changes alone. Patients diagnosed with GDM were either managed on diet and lifestyle changes alone (83 patients) or diet, lifestyle changes, and multiple insulin injections (in 40 cases where

Table 4 Type of diabetes mellitus and treatment administered $(n=\mid 7 I)$

\begin{tabular}{lll}
\hline Event & Cases (n) & Percentage \\
\hline Type of diabetes mellitus & & \\
$\quad$ Gestational diabetes mellitus & 123 & 71.9 \\
Insulin-dependent diabetes mellitus & 21 & 12.3 \\
Impaired glucose metabolism & 27 & 15.8 \\
$\begin{array}{l}\text { Treatment offered } \\
\text { Insulin injections and diet* }\end{array}$ & 61 & \\
Dietary control only* & 110 & 64.7 \\
\hline
\end{tabular}

Notes: All patients with insulin-dependent diabetes mellitus (type I diabetes mellitus) were managed with insulin injections and diet. Forty patients with gestational diabetes mellitus were managed with insulin injections and diet, and the other 83 patient with gestational diabetes mellitus were managed with diet. All patients with impaired glucose tolerance were managed with diet only. *Increased physical activity was emphasized as part of the treatment in all patients with diabetes mellitus (both gestational diabetes mellitus and type I diabetes mellitus) and impaired glucose tolerance (impaired glucose metabolism). In this table, insulin-dependent diabetes mellitus is the same as type I diabetes mellitus. satisfactory control was not achieved with the modalities of treatment already stated). The lifestyle changes included increased physical activity in the hospital and at home, and regular weight checks at home/hospital to ensure that rapid weight increases during the pregnancy did not occur.

Apart from higher incidences of premature rupture of membranes in 26 cases (15.2\%), oligohydramnios (12, 7.0\%), polyhydramnios $(8,4.7 \%)$, placenta previa $(8,4.7 \%)$, preeclampsia $(4,2.3 \%)$, and postpartum hemorrhage $(6,3.5 \%)$ were also seen in the study population (Table 5), and the overall trends in the incidences of the maternal complications in the study and control populations were low and comparable. Thirty-one cases (18.1\%) of the control population were postdate; postdate is the most common indication for induction of labor at the Maternity Hospital in Kuwait. None of the pregnancies in the study group were allowed to go beyond the estimated date of delivery. The incidences of complications were generally low, and further analysis into the diabetic subgroups was considered unnecessary as the incidences would have been even lower.

There was no significant difference in the mean fetal birth weight in the study and control patients $(3,317.49 \pm 620.042$ vs $3,223.58 \pm 550.390 \mathrm{~g} ; P=0.139)$, although the gestational age at delivery was significantly higher in the control group (39.02 \pm 1.834 vs $38.62 \pm 1.773$ weeks; $P<0.0001)$. There was no significant difference in the incidences of fetal macrosomia (fetal weight $>4000.00 \mathrm{~g}$ ) between the study and control patients $(9.36 \%$ vs $7.01 \% ; P=0.512)$. The incidences of operative delivery were significantly higher in the study group than the control group: cesarean section, $44.4 \%$ vs

Table 5 Antenatal/intrapartum complications: study and control population

\begin{tabular}{|c|c|c|c|}
\hline Complication & $\begin{array}{l}\text { Study } \\
(n=|7|)\end{array}$ & $\begin{array}{l}\text { Control } \\
(n=|7|)\end{array}$ & P-value \\
\hline $\begin{array}{l}\text { Premature rupture } \\
\text { of membranes }\end{array}$ & $26(15.2)$ & $14(8.2)$ & NS \\
\hline Oligohydramnios & $12(7.0)$ & $3(1.8)$ & NS \\
\hline Preeclampsia & $4(2.3)$ & $2(1.2)$ & NS \\
\hline Polyhydramnios & $8(4.7)$ & $2(1.2)$ & NS \\
\hline Placenta previa & $8(4.7)$ & $0(0.0)$ & $0.007^{*}$ \\
\hline $\begin{array}{l}\text { Intrauterine growth } \\
\text { restriction }\end{array}$ & $6(3.5)$ & $0(0.0)$ & $0.03^{*}$ \\
\hline Threatened miscarriage & $4(2.3)$ & $2(1.2)$ & NS \\
\hline Urinary tract infection & $4(2.3)$ & $2(1.2)$ & NS \\
\hline Postpartum hemorrhage & $6(3.5)$ & $3(1.8)$ & NS \\
\hline Post dates & $0(0.0)$ & $31(18.1)$ & NS \\
\hline
\end{tabular}

Notes: Data are expressed as number (\%). Five of the patients with placenta previa gave a history of previous multiple cesarean sections. Intrauterine growth restriction was recorded mainly in patients with type I diabetes mellitus and preeclampsia. *Indicates statistically significant.

Abbreviation: NS, not significant. 
$33.3 \%(P=0.046)$, and ventouse delivery, $8.85 \%$ vs $5.9 \%$ $(P=0.047$; Table 6). The 5-minute Apgar scores in both groups were comparable, but the percentage of babies admitted to the Special Care Baby Unit in the study group was three times higher than in the control group (23.3\% vs $7.01 \%$ ), and more babies in the study group were also admitted into the Neonatal Intensive Care Unit (4.7\% vs 0\%). There were three cases each of shoulder dystocia and Erb's palsy in the study population, all in patients presenting with GDM; no such complications were seen in the control group. There was no perinatal death (stillbirths and early neonatal deaths) in the study group, although there was one perinatal death (stillbirth) in the control group, resulting from placental abruption.

Data obtained from further analysis of the management of the diabetic subgroups demonstrated that the gestational age at delivery for type 1 diabetes mellitus was the lowest of all the three subgroups and was significantly lower when compared with the control group ( $P=0.027$; Table 7 ). The incidences of operative delivery (cesarean section and ventouse delivery) were higher in the diabetic subgroups when compared with the control group. The mean fetal birth weight of the GDM and type 1 diabetes subgroups was comparable with the control group. The 5-minute Apgar scores of the diabetic subgroups and the control were satisfactory and were all above 7 .

\section{Discussion}

GDM was the most frequently reported clinical type of diabetes mellitus in pregnancy: $71.9 \%$ of the patients presenting with diabetes mellitus in pregnancy in this clinical study were classified as GDM, and $12.3 \%$ patients had insulin-dependent diabetes mellitus (type 1 diabetes mellitus). The incidence of GDM reported in this study is comparable with the incidence of $90 \% 0^{1,8,11}$ and much higher than the rate of $34.8 \%$ previously reported from the subregion. ${ }^{27}$ The prevalence of GDM is increasing worldwide and has been linked to ethnicity/race, maternal age, and increasing obesity, which is a modifiable risk factor. ${ }^{1,8,28,29}$ In the current study, although ethnicity did not play a significant role in the study, the Kuwaiti ethnic group demonstrated the highest incidence of diabetes.

The mean weight at booking and the mean BMI were significantly higher in the study population compared with in the control group $(P<0.0001)$, thereby indicating a higher incidence of obesity in the patients presenting with diabetes mellitus. The mean weight at booking and the BMI of all the three subgroups were also comparable, confirming the occurrence of obesity in all the subgroups of patients presenting with diabetes mellitus in pregnancy. The age and parity of the study patients, as well as of the patients in the subgroups of GDM and type 1 diabetes mellitus, were significantly higher than in the control group. It is common knowledge that the weight of most women of reproductive age increases gradually with increasing age and parity; although these two factors may have played a role in both the study and control patients, leading to the obesity and high BMI reported, they may have had a much greater effect on the study patients, thus contributing to the higher rate of obesity and the higher

Table 6 Events at delivery and fetal outcome: study and control population

\begin{tabular}{|c|c|c|c|}
\hline Events & $\begin{array}{l}\text { Study population } \\
(n=|7|)\end{array}$ & $\begin{array}{l}\text { Control population } \\
(n=17 \mid)\end{array}$ & $P$-value \\
\hline \multicolumn{4}{|l|}{ Mode of delivery } \\
\hline SVD & $80(46.8)$ & $99(57.9)$ & $0.05 I^{*}$ \\
\hline LSCS & $76(44.4)$ & $57(33.3)$ & $0.046 *$ \\
\hline Ventouse & $15(8.8)$ & $10(5.9)$ & $0.047^{*}$ \\
\hline Forceps & $0(0.0)$ & $5(2.9)$ & \\
\hline Gestational age at delivery & $38.62 \pm 1.773$ & $* 39.02 \pm 1.834$ & $<0.000 I^{*}$ \\
\hline \multicolumn{4}{|l|}{ Fetal outcome } \\
\hline Mean birth weight, $g$ & $3,317.49 \pm 620.042$ & $* 3,223.58 \pm 550.390$ & 0.139 \\
\hline Mean Apgar score, 5 min & $8.00 \pm I .182$ & $* 8.04 \pm 1.095$ & 0.745 \\
\hline Mean birth weight $>4500.00 \mathrm{~g}$ & $12(7.01) 716(936)$ & $0(0.00) \quad\} 12(7.01)$ & \\
\hline Mean birth weight $>4000.00 \mathrm{~g}$ & $4(2.30) \quad 510(7.30)$ & $12(7.01)^{5} 12(1.01)$ & \\
\hline Admission to SCBU & $40(23.30)$ & $12(7.01)$ & \\
\hline Fetal anomaly & $2(1.17)$ & $0(0.00)$ & \\
\hline Admission to NICU & $8(4.70)$ & $0(0.00)$ & \\
\hline Shoulder dystocia & $3(1.8)$ & $0(0.00)$ & \\
\hline Erb's palsy & $3(1.8)$ & $0(0.00)$ & \\
\hline
\end{tabular}

Notes: For gestational age at delivery, mean birth weight, and mean Apgar score, data are expressed as mean \pm standard deviation. All other data are expressed as number (\%). *Indicates statistically significant.

Abbreviations: LSCS, lower segment cesarean section; min, minutes; NICU, neonatal intensive care unit; SCBU, special care baby unit; SVD, spontaneous vaginal delivery. 
Table 7 Events at delivery and fetal outcome: diabetic subgroups and control

\begin{tabular}{|c|c|c|c|c|c|}
\hline Event & $\begin{array}{l}\text { Group A, } \\
\text { GDM }(n=\mid 23)\end{array}$ & $\begin{array}{l}\text { Group B, type I } \\
\text { diabetes }(n=2 I)\end{array}$ & $\begin{array}{l}\text { Group C, } \\
\text { IGT }(n=27)\end{array}$ & $\begin{array}{l}\text { Group } D, \\
\text { control }(n=|7|)\end{array}$ & $P$-value \\
\hline Gestational age & $38.70 \pm 1.783$ & $37.76 \pm 2.364$ & $38.93 \pm 0.78 \mid$ & $39.02 \pm 5.643$ & I. 0.094 \\
\hline \multirow[t]{5}{*}{ at delivery, weeks } & & & & & 2. 0.298 \\
\hline & & & & & 3. 0.136 \\
\hline & & & & & 4. $0.040 *$ \\
\hline & & & & & 5. $0.027^{*}$ \\
\hline & & & & & 6. 0.662 \\
\hline \multirow[t]{6}{*}{ Fetal birth weight, $g$} & $3,290.61 \pm 634.96 \mid$ & $3,307.86 \pm 720.969$ & $3,452.50 \pm 440.101$ & $3,223.58 \pm 550.590$ & I. 0.910 \\
\hline & & & & & 2. 0.119 \\
\hline & & & & & 3. 0.346 \\
\hline & & & & & 4. 0.424 \\
\hline & & & & & 5. 0.610 \\
\hline & & & & & 6. $0.040 *$ \\
\hline \multirow[t]{6}{*}{ Apgar score } & $7.86 \pm 1.307$ & $8.14 \pm 0.727$ & $8.52 \pm 0.580$ & $8.04 \pm 1.095$ & I. 0.163 \\
\hline & & & & & 2. $<0.000 I^{*}$ \\
\hline & & & & & 3. 0.214 \\
\hline & & & & & 4. $0.049 *$ \\
\hline & & & & & 5. 0.581 \\
\hline & & & & & 6. $0.001 *$ \\
\hline \multirow[t]{6}{*}{ SVD } & $59(48.0)$ & $13(6 \mid .9)$ & $8(29.6)$ & 99 (57.9) & I. 0.345 \\
\hline & & & & & 2. 0.091 \\
\hline & & & & & 3. 0.117 \\
\hline & & & & & 4. $0.040 *$ \\
\hline & & & & & 5. 0.817 \\
\hline & & & & & 6. $0.007^{*}$ \\
\hline \multirow[t]{6}{*}{$\mathrm{C} / \mathrm{S}$} & $5 I(4 I .4)$ & $8(38.1)$ & $17(63.0)$ & $57(33.3)$ & I. 0.815 \\
\hline & & & & & 2. $0.054^{*}$ \\
\hline & & & & & 3. 0.192 \\
\hline & & & & & 4. 0.144 \\
\hline & & & & & 5. 0.635 \\
\hline & & & & & 6. $0.004 *$ \\
\hline \multirow[t]{6}{*}{ Ventouse } & $13(10.6)$ & - & $2(7.4)$ & $10(5.9)$ & I. 0.215 \\
\hline & & & & & 2. 1.000 \\
\hline & & & & & 3. 0.205 \\
\hline & & & & & 4. 0.497 \\
\hline & & & & & 5. 0.604 \\
\hline & & & & & 6. 0.670 \\
\hline
\end{tabular}

Notes: I, A versus B; 2, A versus C; 3, A versus D; 4, B versus C; 5, B versus D; and 6, C versus D. Data are expressed as mean \pm standard deviation and number (\%). A Chi-square test was used for SVD, C/S, and ventouse. *Indicates statistically significant.

Abbreviations: GDM, gestational diabetes mellitus; C/S, lower-segment cesarean section; IGT, impaired glucose tolerance; SVD, spontaneous vaginal delivery.

BMI of the study group. Many authors have emphasized the strong link between GDM and obesity. 1,8,30

The incidence of diabetes mellitus (particularly type 2 diabetes) and obesity is increasing in Kuwait, particularly in the Kuwaiti ethnic group (14.5\%), ${ }^{24}$ and this may be contributing directly to the high incidence of GDM in pregnancy reported in this study. It is pertinent to emphasize that in the current study, a past medical history of type 2 diabetes mellitus and GDM was volunteered by $62.6 \%$ and $22.8 \%$ of the patients, respectively. One could deduce from the information in the past history that many of our patients presenting as GDM were most probably previous cases of type 2 diabetes mellitus who became unmasked by the diagnostic screening in pregnancy. The association between GDM and type 2 diabetes mellitus is further emphasized by previous reports that have stated that $5 \%-10 \%$ of GDM could be previously undetected cases of type 2 diabetes mellitus ${ }^{31}$ and $10 \%-15 \%$ of women with GDM develop type 2 diabetes within 5 years. ${ }^{32}$

Patients with diabetes mellitus in pregnancy in this study did not present with classical triad of polyphagia, polydipsia, and polyuria. The symptomatology was vague and the diagnosis was usually confirmed after diagnostic tests (OGTT). Whereas diet supplemented with increased physical activity/ blood glucose monitoring is the mainstay of the treatment of GDM, ${ }^{1,4,8,33}$ insulin injections combined with dietary control and increased physical activity and blood sugar monitoring 
are very important additional measures in the treatment of diabetes mellitus in pregnancy. ${ }^{1,4,6,8,10,17,23,28}$ In the current study, $64.3 \%$ of the patients were managed on diet and enhanced physical activity, and $35.7 \%$ were managed on insulin injections, diet, and increased physical activity.

Although there was no definite information on prepregnancy counseling in our patients, it is pertinent to state that $49.2 \%$ of the patients were admitted in the first trimester (8-12 weeks) for careful control of diabetes, which usually included blood glucose monitoring and addition of insulin injections as required, a finding that tends to exclude any significant pre-pregnancy counseling/control of blood glucose. In all, $88.5 \%$ of the patients were admitted during pregnancy for blood glucose monitoring and diabetic control, including monitoring of glycosylated hemoglobin $\mathrm{A}_{1 \mathrm{c}}$ levels and ensuring that they were maintained in the normal range. The mean weight gained all through the pregnancy was significantly lower in the study population $(P<0.009)$; this trend was also demonstrated in the subgroups of diabetes mellitus (GDM and type 1 diabetes mellitus), as reflected in Table 2, subsequent to further analysis of the study population. This indicates a positive effect of the treatment measures introduced in the care of the patients, which placed great emphasis on the reduction of weight gained in pregnancy.

An increased incidence of maternal complications such as chronic hypertension and preeclampsia have been reported in pregnancies complicated by diabetes mellitus. ${ }^{1,8,28,33}$ The incidence of preeclampsia in previous studies on GDM has ranged from $4.8 \%{ }^{34}$ to $15 \%{ }^{10}$; the efficacy of glycemic control has also been associated with the incidence of preeclampsia: Whereas a satisfactory fasting blood glucose was associated with $7.8 \%$ incidence of preeclampsia, an unsatisfactory fasting blood glucose was associated with a higher incidence of preeclampsia $(13.8 \%) .{ }^{35}$ In our study, the incidence of preeclampsia $(2.3 \%)$ was much lower than the incidences reported earlier; this may be a result of the overall adequate glycemic control that was reported in our study. The other maternal complications reported in this study (oligohydramnios, intrauterine growth restriction, placenta previa, and postpartum hemorrhage) were directly related to preexisting morbidities in some of the patients in our study population, such as the higher incidence of repeat cesarean sections in the study populations (diabetic patients and preexisting type 1 diabetes mellitus in some patients).

There was a significantly higher incidence of cesarean section $(P=0.046)$ and ventouse delivery $(P=0.047)$ in the study population compared with in the control population (the control patients were admitted for induction of labor, an event usually associated with increased rates of operative delivery, such as cesarean sections and instrumental deliveries), in spite of the gestational age at delivery being significantly higher in the control population $(P<0.0001)$ and there being no significant difference in the birth weight of the babies $(P=0.139)$. The incidences of operative delivery were also higher in the three subgroups of diabetes mellitus when compared with the control group. Some studies on GDM have reported a reduction in the incidence of cesarean section ${ }^{19}$ or no change in the incidence of cesarean section, ${ }^{10}$ whereas some other reports have linked an increased incidence of cesarean section with GDM, ${ }^{6,28}$ especially where fetal macrosomia is present, as was observed in this study. It is pertinent to emphasize here again that there was no significantly increased incidence of fetal macrosomia in the study (the incidences of fetal macrosomia in the study and control populations were not significantly different; $P=0.512$ ). A number of other factors, apart from the diagnosis of diabetes mellitus in our study population, may have contributed to the higher incidence of cesarean sections reported in the study population. These include the higher BMI, age, and parity of the study population compared with the control patients.

The Apgar scores of the study and control patients were comparable and satisfactory. However, significantly higher incidences of newborn admissions to the Special Care Baby Unit and Neonatal Intensive Care Unit were reported in the study population. These admissions may have been more readily encouraged because the attending neonatologists were aware of the diagnosis of diabetes mellitus in the mothers and they were taking extra measures to ensure adequate care and monitoring for these newborns, especially in the light of the fact that hypoglycemia is a well-documented risk in babies of diabetic mothers. The incidence of hypoglycemia in neonates of diabetic mothers has been quoted as $15 \%-25 \% .^{36,37}$ No major adverse effects were reported in these newborn babies. The incidence of shoulder dystocia (1.8\%) and Erb's palsy (1.8\%) was quite low and comparable to data from previous reports. ${ }^{6,10}$ There were no perinatal deaths reported in the study.

GDM was the most predominant type of diabetes mellitus in pregnancy seen in the current study and has been associated with adverse fetal and maternal outcomes. ${ }^{4,6,8,10,19,28}$ Such outcomes will be particularly increased in the absence of treatment or adequate control of blood glucose in GDM. ${ }^{23}$ In our study, adequate glycemic control was generally attained, which would have played a role in the lower maternal and perinatal morbidity reported, and thus a less adverse fetal and maternal outcome. In the absence of adequate or effective pre-pregnancy counseling, most patients with type 2 diabetes 
mellitus will present in pregnancy as GDM. ${ }^{28,30,32}$ In our study, there was quite a high incidence of previous history of type 2 diabetes mellitus. Hence, one could deduce that the majority of our cases of GDM were probably cases of type 2 diabetes mellitus unmasked by the increased screening for diabetes in pregnancy, especially in the absence of significant pre-pregnancy counseling/care in our center, as alluded to earlier.

The main weakness of our study was the fact that the study was conducted on patients presenting in the labor ward, which was the final phase of the obstetric history of these patients in the index pregnancy under review, and this may have affected some of the antenatal data collected on these patients, as these antenatal data were collected retrospectively from the patients and from their case records. The monitoring of the patients in labor has contributed positively to our ability to document very accurately the intrapartum and postpartum events. This opportunity, which could be seen as the major strength of this study, has enabled us to document the acute events of labor and the puerperium in the diabetic patients who were studied. A longitudinal study on diabetes mellitus in pregnancy, commencing prenatally where possible and extending through the antenatal, intrapartum periods, and ending in the puerperium is planned for the future.

GDM is the main clinical type of presentation of diabetes in pregnancy in our department, and the clinical triad of polyphagia, polydipsia, and polyuria, the main hallmark of the presentation of clinical diabetes mellitus, was not reported in this study. Emphasis on effective glycemic control and close monitoring of our patients has contributed positively and had a positive effect on the favorable maternal and perinatal outcome reported in this study. The high incidence of cesarean section calls for greater drive to identify areas of weakness in the overall care of our patients.

\section{Acknowledgments}

We are grateful to all our colleagues for allowing us to include their patients in our study and also for their cooperation throughout the period of our study. This was an unfunded study.

\section{Disclosure}

The authors report no conflicts of interest in this work.

\section{References}

1. Menato G, Bo S, Signorile A, et al. Current management of gestational diabetes mellitus. Expert Rev of Obstet Gynecol. 2008;3(1):73-91.

2. Cunningham FG, Leveno KJ, Bloom SL, Hauth JC, Rouse DJ, Spong CY. Diabetes Williams Obstetrics. 23rd ed. New York: McGraw Hill Medical Publishing, 2010;1104-1125.
3. Lethbridge-Cejku M, Schiller JS, Bernadel L. Summary health statistics for US adults: National Health Interview Survey, 2002. Vital Health Stat 10. 2004;(222):1-151.

4. American College of Obstetricians and Gynecologists Committee on Practice Bulletins - Obstetrics. ACOG Practice Bulletin. Clinical management guidelines for obstetrician-gynecologists. Number 30, Sep 2001 (replaces Technical Bulletin Number 200, Dec 1994). Gestational diabetes. Obstet Gynecol. 2001;98(3):525-538.

5. American Diabetes Association. Diagnosis and classification of diabetes mellitus. Diabetes Care. 2005;28 Suppl 1:S37-S42.

6. Greene MF, Solomon CG. Gestational diabetes mellitus - time to treat. N Engl J Med. 2005;352(24):2544-2546.

7. Hedderson MM, Williams MA, Holt VL, Weiss NS, Ferrara A. Body mass index and weight gain prior to pregnancy and risk of gestational diabetes mellitus. Am J Obstet Gynecol. 2008;198(4):409. e1-e7.

8. Moore TR. Diabetes mellitus and pregnancy. Medscape.com. eMedicine.2010. Available from: http://emedicine.medscape.com/ article/127547-overview. Accessed November 1, 2013.

9. Hoffman L, Nolan C, Wilson JD, Oats JJ, Simmons D. Gestational diabetes mellitus - management guidelines. The Australasian Diabetes in Pregnancy Society. Med J Aust. 1998;169(2):93-97.

10. Crowther CA, Hiller JE, Moss JR, McPhee AJ, Jeffries WS, Robinson JS; Australian Carbohydrate Intolerance Study in Pregnant Women (ACHOIS) Trial Group. Effect of treatment of gestational diabetes mellitus on pregnancy outcomes. $N$ Engl J Med. 2005; 352(24):2477-2486.

11. Dabelea D, Snell-Bergeon JK, Hartsfield CL, Bischoff KJ, Hamman RF, McDuffie RS; Kaiser Permanente of Colorado GDM Screening Program. Increasing prevalence of gestational diabetes mellitus (GDM) over time and by birth cohort: Kaiser Permanente of Colorado GDM Screening Program. Diabetes Care. 2005;28(3):579-584.

12. Hikel KM. Preparing Your Patients for Motherhood - An Update on Preconception Care. An Expert Interview With Peter S. Bernstein, MD, MPH. Available from: http://www.medscape.com/viewarticle/724434. Accessed November 1, 2010.

13. Cuningham FG, Leveno KJ, Bloom SL, Hanth JC, Gilstrap LC, Wenstron KD, editors. Preconceptional Counseling. Williams Obstetrics. 22nd ed. New York: McGraw Hill Medical Publishing. 2005:189-200.

14. Becerra JE, Khoury MJ, Cordero JF, Erickson JD. Diabetes mellitus during pregnancy and the risks for specific birth defects: a populationbased case-control study. Pediatrics. 1990;85(1):1-9.

15. de Valk HW, van Nieuwaal NH, Visser GH. Pregnancy outcome in type 2 diabetes mellitus: a retrospective analysis from The Netherlands. Rev Diabet Stud. 2006;3(3):134-142.

16. Dunne F, Brydon P, Smith K, Gee H. Pregnancy in women with Type 2 diabetes: 12 years outcome data 1990-2002. Diabet Med. 2003;20(9): 734-738.

17. Kapoor N, Sankaran S, Hyer S, Shehata H. Diabetes in pregnancy: a review of current evidence. Curr Opin Obstet Gynecol. 2007;19(6) 586-590.

18. Cundy T, Gamble G, Townend K, Henley PG, MacPherson P, Roberts AB. Perinatal mortality in Type 2 diabetes mellitus. Diabet Med. 2000;17(1):33-39.

19. Landon MB, Spong CY, Thom E, et al; Eunice Kennedy Shriver National Institute of Child Health and Human Development Maternal-Fetal Medicine Units Network. A multicenter, randomized trial of treatment for mild gestational diabetes. N Engl J Med. 2009;361(14): 1339-1348.

20. Rowan JA, Hague WM, Gao W, Battin MR, Moore MP; MiG Trial Investigators. Metformin versus insulin for the treatment of gestational diabetes. N Engl J Med. 2008;358(19):2003-2015.

21. Rowan JA, Gao W, Hague WM, McIntyre HD. Glycemia and its relationship to outcomes in the metformin in gestational diabetes trial. Diabetes Care. 2010;33(1):9-16.

22. Royal College of Obstetricians and Gynaecologists. Scientific Advisory Committee Opinion Paper. Diagnosis and Treatment of Gestational Diabetes. 2011: Available from: http://www.rcog.org.uk/files/rcog-corp/ uploaded-files/SIP_No_23.pdf. Accessed July 8, 2011. 
23. Langer O, Yogev Y, Most O, Xenakis EM. Gestational diabetes: the consequences of not treating. Am J Obstet Gynecol. 2005;192(4): 989-997.

24. Abdella N, Al Arouj M, Al Nakhi A, Al Assoussi A, Moussa M. Non-insulin-dependent diabetes in Kuwait: prevalence rates and associated risk factors. Diabetes Res Clin Pract. 1998;42(3):187-196.

25. Abdella N, Al Nakhi A, Al Arouj M, Assoussi A, Moussa M. Impact of the 1997 American Diabetes Association criteria on classification of glucose intolerance among Kuwaitis below 50 years of age. Acta Diabetol. 1999;36(3):133-140.

26. World Health Organization. Definition and diagnosis of diabetes mellitus and intermediate hyperplycemia; $A$ report of $W H O / I D F$ consultation. Geneva: World Health Organization; 2006. Available from: http://www. who.int/diabetes/publications/Definition\%20and\%20diagnosis $\% 20$ of\%20diabetes_new.pdf. Accessed November 1, 2013.

27. Dafallah SE, Yousif EM. Diabetes mellitus during pregnancy. Fetal outcome. Saudi Med J. 2004;25(12):2041-2042.

28. Kim C. Gestational diabetes: risks, management, and treatment options. Int J Womens Health. 2010;2:339-351.

29. Ferrara A, Kahn HS, Quesenberry CP, Riley C, Hedderson MM. An increase in the incidence of gestational diabetes mellitus: Northern California, 1991-2000. Obstet Gynecol. 2004;103(3):526-533.

30. Kim SY, England L, Wilson HG, Bish C, Satten GA, Dietz P. Percentage of gestational diabetes mellitus attributable to overweight and obesity. Am J Public Health. 2010;100(6):1047-1052.
31. Harris MI. Gestational diabetes may represent discovery of preexisting glucose intolerance. Diabetes Care. 1988;11(5):402-411.

32. Kim C, Newton KM, Knopp RH. Gestational diabetes and the incidence of type 2 diabetes: a systematic review. Diabetes Care. 2002;25(10): $1862-1868$

33. ACOG Committee on Practice Bulletins. ACOG Practice Bulletin. Clinical Management Guidelines for Obstetrician-Gynecologists. Number 60, March 2005. Pregestational diabetes mellitus. Obstet Gynecol. 2005;105(3):675-685.

34. Hyperglycemia and Adverse Pregnancy Outcome (HAPO) Study Cooperative Research Group. Hyperglycemia and Adverse Pregnancy Outcome (HAPO) study: preeclampsia. Am J Obstet Gynecol. 2010;202(3): 255. e1-e7.

35. Yogev Y, Xenakis EM, Langer O. The association between preeclampsia and the severity of gestational diabetes: the impact of glycemic control. Am J Obstet Gynecol. 2004;191(5):1655-1660.

36. Moore TR, Smith CV, Khardori R, Talavera F, Warshak C, Zurawin RK. Diabetes Mellitus and Pregnancy. Available from: http://emedicine. medscape.com/article/127547-overview. Accessed July 22, 2013.

37. Alam M, Raza SJ, Sherali AR, Akhtar AS. Neonatal complications in infants born to diabetic mothers. J Coll Physicians Surg Pak. 2006;16(3):212-215.
International Journal of Women's Health

\section{Publish your work in this journal}

The International Journal of Women's Health is an international, peerreviewed open-access journal publishing original research, reports, editorials, reviews and commentaries on all aspects of women's healthcare including gynecology, obstetrics, and breast cancer. The manuscript management system is completely online and includes

\section{Dovepress}

a very quick and fair peer-review system, which is all easy to use. Visit http://www.dovepress.com/testimonials.php to read real quotes from published authors. 